\title{
Wizualna analiza dyskursu na Instagramie - możliwości i ograniczenia
}

\author{
Agnieszka Kampka \\ SGGW
}

DOI: http://dx.doi.org/10.18778/1733-8069.16.4.05

\section{Słowa kluczowe: \\ wizualność, \\ Instagram, \\ analiza dyskursu, \\ multimodalność, nowe \\ media}

\begin{abstract}
Abstrakt: W artykule omówiono wyzwania, jakie przed badaczami dyskursu stawiają nowe media. Autorka przedstawia charakterystykę Instagrama jako przestrzeni komunikacji oraz wykorzystanie go w dyskursie politycznym. Na podstawie dotychczasowych badań oraz na przykładzie analizy profili europejskich prezydentów jako największe trudności w badaniach tej platformy społecznościowej zidentyfikowane zostały: nierozłączność obrazu i tekstu, konieczność uwzględnienia szerokiego kontekstu technologicznego i kulturowego oraz wynikająca z tego potrzeba interdyscyplinarnego podejścia.
\end{abstract}

Agnieszka Kampka, dr hab., jest socjologiem, pracuje w Instytucie Nauk Socjologicznych i Pedagogiki SGGW w Warszawie. Jej zainteresowania badawcze dotyczą retoryki politycznej i wizualnej, komunikacji społecznej, debaty i dyskursu publicznego, socjologii mediów.

\section{Adres kontaktowy:}

Instytut Nauk Socjologicznych i Pedagogiki

Wydział Socjologii i Pedagogiki SGGW

ul. Nowoursynowska 166, 02-787 Warszawa

e-mail: agnieszka_kampka@sggw.edu.pl

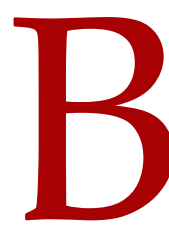

yły australijski premier, Tony Abbott, powiedział kiedyś lekceważąco, że aktywność w mediach społecznościowych przypomina graffiti, a nikt nie powinien przejmować się relacjonowaniem tego, co zostało namazane sprayem na ścianie (MacDowall, de Souza 2018: 4). Fala prześmiewczych postów i hasztagów, która przetoczyła się przez Twitter, Facebook i Instagram w reakcji na tę wypowiedź, pokazała, jak ważną siłą polityczną w rękach obywateli i polityków stały się media społecznościowe. Trudno 
dziś wyobrazić sobie refleksję nad dyskursem politycznym bez uwzględnienia tego, co się w nich dzieje. Jest to jednak przestrzeń bardzo trudna dla badaczy dyskursu. Celem tego artykułu jest omówienie wyzwań, które przed nimi stają gdy chca zmierzyć się z materiałem badawczym zaczerpniętym z jednej z najszybciej zyskujących popularność platform społecznościowych - Instagrama.

Kanwą mojej refleksji są dylematy i wybory, jakie towarzyszyły mi w badaniu instagramowych profili europejskich prezydentów. Przeanalizowałam około 1200 zdjęć zamieszczonych w 500 postach opublikowanych przez prezydentów dziesięciu europejskich państw, wykorzystując narzędzia semiotyki społecznej (van Leeuven, Jewitt 2004; Kress, van Leeuwen 2006) i retoryki wizualnej (Foss 1994; 2005; Olson, Finnegan, Hope 2008; Mariani 2019). Wyniki tych analiz i szczegółowy opis metodologii omawiam w innym miejscu (Kampka 2019), $\mathrm{w}$ niniejszym tekście skupiam się natomiast na elementach, które należy uwzględniać przy projektowaniu takich analiz. Jak pokazuje przegląd literatury przedmiotu i dotychczasowych badań, analiza wizualnego dyskursu mediów społecznościowych wymaga interdyscyplinarnego podejścia, korzystania z dorobku nauk ścisłych (przede wszystkim informatyki), teorii i historii sztuki, historii i teorii fotografii, psychologii, socjologii, marketingu, studiów kulturowych, medioznawstwa, a w przypadku dyskursu politycznego, także teorii polityki czy stosunków międzynarodowych.

Zacznę od przedstawienia Instagrama jako przestrzeni komunikacji, wskazując problematyczne kwestie, jakie stają przed uczonymi pragnącymi badać wizualny dyskurs w mediach społecznościowych. Następnie scharakteryzuję specyfikę wizualnej komunikacji politycznej, z jaką mamy do czynienia w sieci.
Omawiane przeze mnie badania i wskazywane problemy odnoszą się przede wszystkim do tematów i materiałów, które stanowią część wspólną następujących zbiorów: dyskursu polityki (Czyżewski, Kowalski, Piotrowski 1997), dyskursu wizualnego (Rose 2010) i dyskursu nowych mediów (KhosraviNik, Unger 2015; KhosraviNik 2018). Odwołując się do literatury przedmiotu, omówię konsekwencje wynikające z wyboru przyjętej perspektywy: nastawionej na media lub skoncentrowanej na polityce.

\section{Instagram jako przestrzeń komunikacji}

Instagram to darmowa aplikacja i serwis społecznościowy, w którym po założeniu konta można dzielić się z innymi użytkownikami zdjęciami i krótkimi filmami. Zdjęcia te i filmy można opisać, dodając do tego hasztagi (słowa lub hasła poprzedzone znakiem \#, które pozwalają na szybkie znalezienie postów o tej samej tematyce). Instagram umożliwia prostą edycję zdjęć i nakładanie na nie filtrów. Użytkownicy moga polubić i komentować publikacje, a także obserwować dane konto, co oznacza, że są na bieżąco informowani o aktywności nadawcy.

Instagram jest platformą społecznościową, której popularność w ostatnich latach rośnie skokowo. W końcu 2019 roku co miesiąc korzystało z niego miliard osób, z czego połowa logowała się każdego dnia (Newberry 2019). W Polsce w styczniu 2020 korzystało z niego 7,3 mln osób, co stanowi $22 \%$ wszystkich polskich internautów (Kuchta-Nykiel 2020). Użytkownicy to w przeważającej części ludzie młodzi (15-34 lata) (Statista 2020, Gemius/ PBI 2019), nieznacznie więcej jest wśród nich kobiet (52\%) (Newberry 2019). Jak pokazują dane ze Stanów Zjednoczonych, przekrój użytkowników Instagrama lepiej oddaje rasowe i ekonomiczne zróżnicowanie społeczne niż na przykład Twittera 
(który jest bardzo ważnym medium w komunikacji politycznej), ale przewaga młodszych użytkowników nie pozwala traktować ich jako reprezentatywnej grupy (Laestadius 2017). Fakt, że Instagram stał się medium dostępnym i używanym przez osoby z niższych klas społecznych, niemające wyższego wykształcenia, z niższymi zarobkami, będące przedstawicielami różnych grup mniejszościowych sprawia, że jest to bardzo istotny kanał komunikacji polityków z potencjalnymi wyborcami. Otwiera się tu nowa przestrzeń kontaktu z młodymi wyborcami. Jest to też szansa dla polityków budujących swój przekaz na wątkach populistycznych i zwracających się do wyborców, którzy mogą czuć się pokrzywdzeni czy marginalizowani. Obie grupy adresatów wymagają od polityków nowych praktyk dyskursywnych. W perswazyjnej komunikacji (a z taką mamy do czynienia w dyskursie politycznym) użycie Facebooka, Twittera, Instagrama lub Snapchata to strategiczny wybór, który wiąże się z publikowaną treścią, zakładaną publicznością i pożądanym efektem (Bossetta 2018). Ponieważ Instagram wyróżnia konieczność dołączenia obrazu lub krótkiego wideo do każdego postu, wymaga to również świadomej decyzji estetycznej.

Każda z platform społecznościowych (Facebook, Twitter, Instagram, Snapchat, TikTok) ma własną, niepowtarzalną mieszankę stylu, gramatyki i logiki, które razem tworzą nowy gatunek komunikacji. W literaturze używane jest określenie platform vernacular (Gibbs i in. 2014), czyli to, co na danej platformie jest normalne i codzienne; „zwyczajność” tę tworzą możliwości techniczne, architektura danego medium oraz przyzwyczajenia i zachowania użytkowników (por. Wielgosz 2017). Innymi słowy - jakiego rodzaju zdjęcia/filmy/grafiki należy publikować, jak je opisywać, jak na nie reagować, jaką interakcje prowadzić z innymi użytkownikami, co jest typowym zachowaniem, co zaś będzie brzmiało i wyglądało nieodpowiednio lub fałszywie.

Choć, jak zostało to już wspomniane, przekaz na Instagramie jest multimodalny, to jednak, co pokazuja dane (Laestadius 2017), obraz pozostaje zdecydowanie najważniejszym kanałem przekazu. W przypadku postów polityków komentarze, po pierwsze, na ogół nie są zbyt liczne, po drugie, zwykle nie prowadzą do rozwiniętych dyskusji. Przy czym warto zaznaczyć, że spostrzeżenia te dotyczą komunikacji politycznej i oficjalnych kont polityków czy instytucji publicznych.

Podobnie specyficzna jest rola hasztagów, to również przejaw platform vernacular. $\mathrm{O}$ ile hasztag na Twitterze porządkuje tematykę dyskusji, hasztagi na Instagramie znacznie częściej budują kontekst danego zdjęcia. Linnea Laestadius (2017) przytacza dwa przykłady. Pierwszy to hasztag \#Ferguson, związany z zastrzeleniem przez policję w Ferguson czarnoskórego Michaela Browna. Na Twitterze hasztag ten pojawiał się przy wypowiedziach odnoszących się bezpośrednio do tej sprawy, posty na Instagramie natomiast związane były z szerszymi kwestiami dotyczącymi rasy i praw obywatelskich. Drugi przykład to hasztag \#Ebola. Opatrzone nim zdjęcia na platformie Flickr pokazywały przede wszystkim wybuch epidemii w 2014 roku, chorych i pracowników medycznych z Zachodniej Afryki. Na Instagramie pojawiło się zaś wiele postów zupełnie niezwiązanych z tematem, zawierających żarty czy memy na temat wirusa, co z kolei dowodzi, że Instagram jest jednak medium społecznościowym służącym komunikacji między użytkownikami, a nie tylko prezentacji czy archiwizacji zdjęć.

Jednym z najważniejszych celów użytkowników Instagrama jest dokumentowanie swojego codzien- 
nego życia, co potwierdza także określanie miejsc, w których robione są zdjęcia, geotagi występują na Instagramie częściej niż na innych platformach. Częściej można tu zaobserwować także tworzenie się małych grup przyjaciół „klikających” nawzajem swoje posty - takich sytuacji na Instagramie jest więcej niż na przykład na Twitterze (Laestadius 2017).

Lev Manovich (2017) wyróżnia trzy typy zdjęć zamieszczanych na Instagramie: zwykłe, profesjonalne i wystudiowane (styled). Głównym celem zwyczajnych zdjęć jest wizualne dokumentowanie i dzielenie się doświadczeniami, sytuacjami, portretowanie osób i grup. W tym sensie zdjęcia te przypominają dawne rodzinne fotografie robione przez członków rodziny przy różnych okazjach. Instagram zatem wzmocnił funkcję dokumentacyjną, jaka charakteryzowała fotografię od jej początków. Filtry udostępniane przez aplikację pozwalają dodatkowo - między innymi za pomocą koloru czy kontrastu zintensyfikować sam zapis przeżyć. W przypadku zdjęć zwyczajnych mamy też do czynienia ze złymi fotografiami $\mathrm{w}$ sensie estetycznym czy technicznym (kadrowanie, ostrość itp.), ale użytkownicy nie zawsze są tego świadomi. Zresztą nad wartością estetyczną góruje tu wartość dokumentacyjna (Manovich 2017: 52). Manovich posługuje się pojęciem „instagramizmu” - chodzi o sposób patrzenia, pokazywania rzeczywistości, estetykę i wrażliwość wizualną, która, co warto dodać, dotyczy już nie tylko samych zdjęć, ale także projektowania przestrzeni (np. w kawiarni), które będą dobrze prezentowały się na fotografii. Użytkowników Instagrama raczej nie obchodzą techniczne szczegóły zdjęć, one są ważne dla osób zainteresowanych fotografią jako taką (co widać, gdy porównamy Instagram i Flickr). Sam Instagram nie zachęca użytkowników do rozwijania umiejętności fotografowania, ale raczej do użycia odpowiednich filtrów, by upiększyć zdjęcie. Zdjęcie na Instagramie ma charakter użytkowy, służy autoprezentacji lub nawiązaniu interakcji i o tym też należy pamiętać w badaniach (Laestadius 2017).

Serwisy społecznościowe mają wiele charakterystycznych atrybutów: trwałość (przechwytywanie i archiwizacja treści), powtarzalność (powielanie treści), skalowalność (szeroka widoczność treści) i możliwość wyszukiwania (dostęp do treści poprzez wyszukiwanie). Jako serwis społecznościowy Instagram jest narzędziem do dystrybucji zdjęć, a obrazy te to przykład „mediów rozprzestrzenialnych", które są udostępniane przez odbiorców do ich własnych celów w ramach kultury uczestnictwa (Zappavigna, Zhao 2017; Jenkins, Ford, Green 2018). Podsumowując różnice między platformami, Lev Manovich (2017: 39) stwierdza, że o ile Twitter służy wymianie linków i informacji, Facebook komunikacji społecznej, Flickr archiwizowaniu zdjęć, to Instagram jest przeznaczony do estetycznej wizualnej komunikacji.

Architektura platformy komunikacyjnej to filozofia danego medium, deklarowana misja i rzeczywisty główny przedmiot zainteresowania, sposób nawigacji, wygląd, stosowane algorytmy, możliwość interakcji, polityka moderowania dyskusji i kontroli zawartości - innymi słowy: kultura danej platformy. Uwzględnienie jej specyfiki jest niekiedy istotniejsze, niż policzenie lajków, udostępnień i komentarzy, co dominuje w wielu analizach (Gerodimos 2019: 63).

Zatrzymajmy się nad normami dyskursywnymi związanymi z wykorzystaniem technologii, czyli społecznie wyuczonymi sposobami zachowania i komunikowania się z technologią. Są one częstym przedmiotem badań na pograniczu nauk społecz- 
nych, technicznych i ścisłych. Soren Poulsen (2018) analizował teksty i zdjęcia zamieszczane na korporacyjnym blogu Instagrama, pytając o założenia twórców i właścicieli platformy: co Instagram mówi sam o sobie, jak się określa i w jaki sposób definiuje swoje zadania. Na blogu tym dominują opisy nowości wprowadzanych na platformie. Wydawać by się mogło, że prezentacja możliwości zarządzania postami i nowych filtrów nie niesie ze sobą szczególnych konsekwencji w wymiarze dyskursywnym, jednak Poulsen przekonująco pokazał, że dobór ilustracji oddaje pewne reguły uczestnictwa, sugeruje, jaka aktywność jest oczekiwana, jakie typy zdjęć najlepiej dopasowane do założeń platformy. Jak się okazuje, korporacyjny blog Instagrama wykorzystuje zdjęcia użytkowników, by kreować dyskurs naturalistycznie, zmysłowo przedstawianego świata. Dominująca estetyka to wyróżnione, wyselekcjonowane rzeczy piękne, zachwycające same z siebie lub poprzez sposób, w jaki są ukazane. Jednocześnie na prezentowanych zdjęciach właściwie nie ma ludzi, nie pojawiają się żadne społeczne aktywności, co stanowi sprzeczność z głoszonym przez korporację celem, jakim jest budowanie wspólnoty użytkowników. Dominuje neutralny, pośredni, niezaangażowany punkt widzenia, widz ma być tylko biernym obserwatorem.

\section{Badanie dyskursu na Instagramie}

Zapoznanie się z założeniami i zasadami funkcjonowania danej platformy jest z całą pewnością pierwszym i niezbędnym krokiem w badaniach dyskursu w mediach społecznościowych. Nie wolno pomijać także zmian w obrębie samej platformy. Nie możemy bowiem traktować mediów społecznościowych jako niezmiennego w swojej naturze zjawiska. Kiedy w Polsce popularność zaczął zdobywać Facebook, swoich użytkowników traciło Grono.pl, ale
Facebook z tamtego okresu był czymś zupełnie innym, niż jest dzisiaj. Zmieniły się techniczne możliwości oferowane przez platformę, ale zmienili się też użytkownicy i sposób działania na Facebooku.

Jak pisze Manovich (2017: 11), skoro istnieją setki milionów sposobów użytkowania Instagrama, trudno jest udzielić jednej odpowiedzi, czym Instagram jest. Analizy potwierdzają kulturowe zróżnicowanie w korzystaniu z niego. Opublikowanych zostało już wiele porad i analiz, jak tworzyć blogi, posty i filmiki. Te teksty pisane przez użytkowników Instagrama, dziennikarzy i ekspertów od marketingu tworzą istotny nurt dyskursu, mający charakter normatywny - co trzeba zrobić, by opublikować najlepszy (czyli wywołujący najżywsze reakcje) post. Manovich słusznie zauważa, że uwaga badaczy koncentruje się na ogół na wyjątkowych użytkownikach, podczas gdy prawdziwe oblicze platformy tworzone jest przez miliony zwykłych internautów. Deklaratywnie i w dyskursie marketingowym Instagram miał być przestrzenią, w której pokazujemy rzeczywisty świat w rzeczywistym czasie, tymczasem, jak dobrze wiemy, przeważająca większość publikacji to starannie zaplanowana i wyreżyserowana produkcja, a nie bieżąca relacja z życia.

Zbieranie danych z Instagrama możliwe jest na trzy sposoby - badacz może pobrać je samodzielnie czy za pośrednictwem specjalistów z Instagram API lub ręcznie pobierać dane z kont użytkowników. Pierwszy sposób jest szybki i pozwala na zgromadzenie dużej ilości danych, choć wymaga pewnych umiejętności technicznych. Drugi sposób - czasochłonny i możliwy do zastosowania jedynie w odniesieniu do niewielkich zbiorów danych - pozwala na dobre zaznajomienie się $\mathrm{z}$ analizowanym materiałem. Pewnym problemem jest możliwa zmiana statusu zdjęć czy profili - w toku badań użytkownicy mogą 
zmienić ustawienia prywatności konta i dotychczas dostępne dane stają się prywatne, co za tym idzie badacz powinien wyłączyć je ze swego zbioru.

Obecnie główne ścieżki badań nad Instagramem to: 1) podejście ilościowe wykorzystujące Big Data, $\mathrm{w}$ tym analizy $\mathrm{w}$ ramach cyfrowej humanistyki, 2) jakościowe analizy małych próbek danych, 3) badania samych użytkowników przy wykorzystaniu wywiadów i metod etnograficznych. We wszystkich tych przypadkach możliwe jest podejście dyskursywne.

Badania wykorzystujące wielkie zbiory danych, związane przede wszystkim z informatyką, służą uchwyceniu prawidłowości $\mathrm{w}$ różnych sposobach używania Instagrama, zachowań związanych ze zdobywaniem popularności, tagowaniem czy popularnością hasztatów. Niektóre z tych badań służą także analizowaniu zjawisk niezwiązanych z samym Instagramem, ale zobrazowanych na nim, jak na przykład palenie. Humanistyka cyfrowa dodatkowo duży nacisk kładzie na wizualną prezentację wyników.

Ilościowe analizy wielkich zbiorów danych pokazują, co użytkownicy robią, połączone zaś z etnograficznymi metodami pozwalają zrozumieć te zachowania oraz intencje i motywacje. Zdaniem Lva Manovicha (2017) lepiej jest, gdy ilościowa analiza poprzedzona jest jakościową, ponieważ wówczas badacz może zweryfikować swoje obserwacje i założenia. Być może uda się odkryć, opisać i zinterpretować wzory, które mogłyby być trudne do wychwycenia lub niemożliwe do zauważenia w badaniach jakościowych (O'Holloran i in. 2018). Analiza Big Data może być bardzo przydatna do badania i wyjaśniania tła, ilościowego kontekstu jakościowo analizowanego wycinka dyskursu. Badania etnogra- ficzne zaś wpisują się w ideę rozprzestrzenialnych mediów, dotyczą one na przykład tego, co użytkownicy robią ze zdjęciami, jak je publikują, komentują, lajkują, udostępniają, jakie kompetencje są uruchamiane przy poszczególnych działaniach (Stíhl, Kaihovirta 2019).

W przypadku analizy profili prezydenckich analiza ilościowa poprzedziła jakościową. Ponieważ nie chodziło o badanie indywidualnych strategii poszczególnych polityków pełniących urząd prezydenta, ale o szukanie wspólnych wzorów prezentacji prezydenckich aktywności, kluczowe było stworzenie spójnego zbioru danych. Po pierwsze, ograniczono zbiór tylko do prezydentów europejskich. Włączenie do zbioru profilu prezydenta USA mogłoby wprowadzać w błąd ze względu na dwie zasadnicze różnice - pozycję prezydenta USA i zakres jego władzy, nieporównywalnie większy niż w przypadku prezydentów europejskich (z wyjątkiem prezydenta Francji), oraz inną skalę znaczenia i użytkowania mediów społecznościowych. Z kolei uwzględnienie przywódców z innych kontynentów wprowadzałoby ogromne zróżnicowanie kulturowe. Po przejrzeniu oficjalnych stron internetowych wszystkich europejskich prezydentów, wybrane zostały profile na Instagramie, do których można było dotrzeć z tych właśnie stron. Na koniec 2018 roku takie konta na Instagramie mieli prezydenci: Austrii, Chorwacji, Czarnogóry, Finlandii, Francji, Irlandii, Polski, Rumunii, Słowenii i Włoch. Następnie z każdego z tych profili wzięto pod uwagę ostatnich 50 postów i wszystkie fotografie w nich zamieszczone. Oznaczało to, że liczba analizowanych zdjęć była różna (od $50 \mathrm{w}$ przypadku prezydenta Irlandii do $247 \mathrm{w}$ przypadku prezydenta Francji). Badany okres obejmował od półtora miesiąca (jak w przypadku prezydentów Austrii czy Czarnogóry) do niemal półtora roku (w przypadku prezyden- 
ta Rumunii). W przypadku komunikacji politycznej ilościowa analiza dotycząca liczby i typów postów, liczby publikowanych zdjęć, częstotliwości publikacji, liczby komentarzy i polubień pozwala na rozpoznanie, na ile ważny jest Instagram, a porównanie intensywności publikacji na Instagramie z innymi kanałami komunikacji (stroną internetową, Twitterem, YouTubem i Facebookiem) pozwala określić, jaki charakter ma przekaz na Instagramie, czy różni się czymś od innych kanałów.

Badania dyskursu związane z mediami społecznościowymi prowadzone są głównie w perspektywie multimodalnej, ale przeważają $\mathrm{w}$ nich analizy dotyczące Twittera lub Facebooka, Instagram jako taki nie był jak dotąd nazbyt często przedmiotem uwagi. Są to na ogół analizy socjologiczne, politologiczne lub medioznawcze. Badacze zajmowali się raczej poszczególnymi grupami użytkowników (np. grupą młodych matek-blogerek - Zappavigna, Zhao 2017) czy politykami w jakimś kraju (Avedissian 2016). Instagram jest jednak na pewno ważny dla tożsamości najmłodszych pokoleń, stąd konieczność namysłu nad ich wrażliwością, estetyką czy raczej estetykami wizualnymi i formami komunikacji.

Pewne tematy przyciągają większą uwagę badaczy. Na pewno należy do nich selfie, które może być analizowane jako gatunek, używany przez określoną grupę użytkowników Instagrama (Zappavigna, Zhao 2017) lub jako multimodalna konstrukcja semiotyczna (Veum, Undrum 2018). Różne typy selfie odczytywane mogą być jako odmienne punkty widzenia wybierane przez nadawców, a zatem selfie nie jest jedynie sposobem autoprezentacji jednostki, ale raczej jej świadomym usytuowaniem się $\mathrm{w}$ interakcjach. Użytkownicy wykorzystują różne źródła semiotyczne, można jednak zaobserwować bardzo silną obecność dominujących wzorów, widocznych w reklamach i bankach zdjęć. Co więcej, wiele podobieństw możemy odnaleźć nie tylko w warstwie wizualnej przekazu, ale także w językowym opisie zdjęć (Veum, Undrum 2018). Poszukiwanie stereotypów jest często podejmowanym tematem badań, zwłaszcza w odniesieniu do stereotypów związanych z płcią, które okazują się silniejsze na Instagramie niż w medialnych reklamach (Döring, Reif, Poeschl 2016), choć bywają wykorzystywane bardzo świadomie (Liu, Suh 2017) lub mogą być odczytywane jako przejaw męskiej dominacji (Rodriguez, Hernandez 2018). Ciekawe analizy dotyczą dyskursów związanych z ciążą (Tiidenberg, Baym 2017) czy karmieniem piersią (Locatelli 2017), w których istotne napięcia tworzone są między tym, co prywatne i publiczne, normalne i odbiegające od normy. Otwiera się tu przestrzeń badawcza dla krytycznej analizy dyskursu.

Instagram badany jest także z perspektywy nauk o zdrowiu, możemy znaleźć analizy zdjęć, hasztagów czy funkcjonowania grup użytkowników skupionych wokół jakiegoś tematu, na przykład ruchu \#bodypositivity (Cohen i in. 2019), anoreksji (Ging, Garvey 2017) czy palenia (Cortese i in. 2018). Pytania badawcze dotyczą zazwyczaj norm zachowań tworzonych w warunkach zwiększonej widzialności i praktyk dyskursywnych, które mogą wspierać lub osłabiać skuteczność kampanii prozdrowotnych. W tych badaniach istotna okazuje się współpraca z psychologami (Cohen i in. 2019), których wiedza i wrażliwość pozwalają dostrzec elementy umykające badaczom z innych dyscyplin.

Przedmiotem analiz są konkretne praktyki, na przykład upamiętnianie zmarłych na Instagramie (Gibbs i in. 2014) lub szersze zjawiska, jak choćby nowe możliwości wytwarzania i udostępniania sztuki (MacDowall, de Souza 2018). Ważnym 
zagadnieniem jest analiza relacji społecznych, na przykład wpływu używania Instagrama na postrzeganie własnych związków i podtrzymywanie więzi (Serafinelli 2017), czy rozmaite gry komunikacyjne podejmowane przez użytkowników, jak choćby świadome naruszanie reguł jako działanie autopromocyjne, co na przykładzie hasztagu \#sorrynotsorry analizował David Matley (2018). Pewna przewaga tematów związanych z kobietami wynika z faktu, że w wielu krajach to właśnie one są najaktywniejszymi użytkowniczkami platformy.

W jakościowych analizach postów na Instagramie stosowane są między innymi metody opracowane przez badaczy semiotyki społecznej, często używanym narzędziem jest lista elementów kompozycyjnych, które pozwalają badać dystans społeczny, nastawienie i charakter kontaktu (Kress, van Leuwen 2006). Jeśli jednak zastanawiamy się nad interpersonalną grą między użytkownikami, którzy chcą przedstawiać siebie i innych, ważne wydają się takie pojęcia jak punkt widzenia czy fokalizacja. Zdjęcie, które ostatecznie prezentujemy innym, służy nawiązaniu relacji między nadawcą i odbiorcą, ale przede wszystkim jest splotem świadomych wyborów nadawcy: co chce pokazać, w jaki sposób, kiedy, po co, czego oczekuje od odbiorców. Odpowiedzi na te fundamentalne pytania pozwalają zrozumieć dyskurs na Instagramie (Zappavigna, Zhao 2017).

\section{Badania skoncentrowane na specyfice medium}

Zastanówmy się teraz, jakie dylematy musi rozstrzygnąć badacz, który w analizie dyskursu pragnie skupić się na kontekście tworzonym przez medium. Jednym z pierwszych ważnych pytań metodologicznych jest to, czy przekaz wizualny, na przykład pojedynczą fotografię na Instagramie, powinniśmy traktować jako statyczny obraz, czy też jako miejsce interakcji. Badania często koncentrują się na sposobie wytwarzania zdjęć lub zdjęciach samych w sobie. Pytanie o strategię komunikacji jest bardzo istotne. Czy nadawca traktuje swoje publikacje jako jednostronny przekaz służący autoprezentacji, czy też chce poprzez swój post zaangażować odbiorców, nawiązać z nimi więź, podjąć jakieś współdziałanie. Skupienie się na krążeniu przekazów to jedno z pilnych wyzwań w badaniach. I nie chodzi tu o działanie algorytmów, które śledzą i kształtują zachowania użytkowników. W podejściu jakościowym ważniejsze jest pytanie o to, jak ludzie rozumieją swoje działania, jaki sens nadają użytkowaniu mediów społecznościowych. Kto i jak ocenia czy interpretuje? Które zdjęcie wywiera jakie wrażenie? Przy czym trzeba pamiętać, że pojedynczy wizualny przekaz nie jest po prostu jednostkowym produktem, wyizolowanym wytworem mediów społecznościowych, ale jest otoczony przez równoległe, podobne lub odmienne debaty, dyskursy, dyskusje mające charakter lub/i wymiar polityczny, prawny, ekonomiczny, technologiczny, kulturowy i społeczny (Highfield, Leaver 2016). Obraz w ujęciu dyskursywnym rozumiemy jako złożony splot elementów technologicznych, estetycznych, politycznych i ekonomicznych (Manghani 2013:154), dlatego potrzebne jest interdyscyplinarne podejście, które pozwoli zbadać, do jakiej wiedzy odwołuje się nadawca i jakie kompetencje musi wykorzystać odbiorca.

Badacze dyskursu zawsze skupiali się na krążeniu idei, ale w mediach społecznościowych to krążenie i wzajemne przenikanie się dyskursów wydaje się być jeszcze bardziej złożone i wielowymiarowe. Przekaz wizualny znajduje się dziś w centrum codziennych i medialnych praktyk, które same w sobie są niezwykle różnorodne, a to oznacza, że bada- 
nia mediów społecznościowych wymagają równie zróżnicowanych pytań i metod badań, uwzględniających odmienności narzędzi i kanałów przekazu.

Do tego dochodzi zróżnicowanie stylistyczne. Analizowany materiał - zdjęcia prezydenckie - łączył w sobie zarówno cechy charakterystyczne dla nieformalnego, wizualno-werbalnego dyskursu mediów społecznościowych, jak i oficjalnego, formalnego, werbalno-wizualnego dyskursu politycznego.

Jak zostało to już wspomniane, kluczowe jest także odkrycie obowiązujących na danej platformie norm, określenie, co w danym dyskursie jest typowe i jak rozpoznać coś, co jest ważne, nowe, odrębne. Co tworzy ramę odniesienia? Uniwersalny dyskurs politycznej reprezentacji, o ile taki w ogóle istnieje? Czy dyskurs na Instagramie? Analiza dyskursu jest zarówno perspektywą, jak i metodą badawczą (Phillips, Hardy 2011). Zajmuje się zjawiskiem społecznym konstruowanym $\mathrm{w}$ praktykach dyskursywnych. Pytanie - co jest tym zjawiskiem w analizowanym przypadku? Nowy kanał komunikacji politycznej? Nowy sposób zdobywania legitymizacji (jak dzieje się to w przypadku urzędujących prezydentów)? Co jest głównym przedmiotem analizy: tekst czy kontekst, w którym tekst funkcjonuje? Czy interesują nas instytucje, działania czy tożsamości? To są pierwsze kroki służące właściwemu zaprojektowaniu badania, uwzględniające zarówno podejście badacza, naturę badanego zjawiska (obiektu), jak i konkretnych oczekiwanych efektów.

Przytoczone wcześniej przykłady analiz materiałów publikowanych na Instagramie pokazują, że jest to baza, z której korzystają uczeni z całego świata. Zestaw ten jednak uświadamia także, jak ważne jest uwzględnianie zróżnicowania kulturowego (Manovich 2017; Karimova 2020). Badając praktyki dyskursywne, musimy cały czas pamiętać, że ten sam hasztag oznacza różne rzeczy w dwóch innych krajach czy w dwóch odmiennych grupach społecznych. Instagram nie jest neutralnym terytorium. W przypadku analizy kont prezydenckich zróżnicowanie kulturowe nakładało się na różnorodność systemów politycznych, kultur politycznych, pozycji prezydenta nie tylko w systemie w ogóle, ale i w danym momencie na scenie politycznej.

Wiele prac dotyczących mediów społecznościowych i mających pionierski charakter opartych jest na źródłach amerykańskich, a zaobserwowane tam prawidłowości nie przekładają się wprost na praktyki użytkowników w innych krajach. Możemy z łatwością zgromadzić artykuły pokazujące przykłady z odległych stron świata, od Syrii przez Czeczenię, Norwegię po Hiszpanię. W każdym z tych krajów politycy zakładają konta na Instagramie. Jeśli na ich działalność nałożymy siatkę kryteriów wypracowanych na bazie kont amerykańskich kongresmenów, to owszem, zaobserwujemy pewne podobieństwa czy różnice, ale jednocześnie możemy pominąć istotne elementy. W przypadku prezydenckich profili uderza na przykład zróżnicowanie stopnia oficjalności zdjęć i ich tematyki. Oglądając profil prezydenta Czarnogóry, można odnieść wrażenie, że patrzy się na szkolną gablotkę z fotograficzną relacją z akademii ku czci. Zdjęcia wyglądają jak z czasów sprzed Internetu. Można wysnuć więc wniosek, że mamy do czynienia $\mathrm{z}$ pewnym niedopasowaniem stylistycznym do medium. Ale czy tak jest $\mathrm{w}$ istocie? Może politycy w Czarnogórze w taki właśnie sposób prezentują się publicznie? Jeśli jednak na oficjalnej stronie premiera Czarnogóry znajdujemy zdjęcia bliższe wzorom komunikacji internetowej, bardziej dynamiczne, mniej formalne, wówczas przekaz wizualny na profilu prezydenckim należy rozpatrywać jako świadomy wybór nadawcy, a nie 
bezwiedne powielanie obowiązujących wzorców. Tu z pomocą mogłyby przyjść takie dyscypliny jak: historia, nauki o polityce, nauki o stosunkach międzynarodowych. Po raz kolejny zatem okazuje się, że interdyscyplinarność badań nad dyskursem potrzebna jest we wszystkich stadiach - począwszy od zbierania materiałów, poprzez konstruowanie pytań badawczych, wreszcie przy interpretacji wyników.

\section{Polityczna komunikacja wizualna w nowych mediach}

Hans Belting (2007: 13) pisał: „Żyjemy z obrazami i rozumiemy świat w obrazach". W świecie, w którym blisko 80\% ludzkości ma dostęp do telewizji, a ponad połowa do Internetu, potęga wizualności w komunikowaniu politycznym jest większa niż kiedykolwiek wcześniej, przekonują Darren G. Lilleker, Anastasia Veneti i Daniel Jackson (2019) we wprowadzeniu do monografii poświęconej społeczno-politycznej sile obrazu.

Komunikacja wizualna w polityce to wszelkie działania, które służą przekazywaniu znaczeń za pomocą obrazu. Publiczne ceremonie, symbole, plakaty i reklamy wyborcze, flagi, koszulki, znaczki - liczba wizualnych przejawów życia politycznego jest ogromna. Wraz z rozwojem nowych mediów pojawiły się kolejne możliwości wykorzystania obrazu w życiu politycznym (Delli Carpini 2017; Owen 2017; Stromer-Galley 2017). Politycy i obywatele porozumiewają się dziś zatem także za pomocą obrazów w sieci, mogą to być zdjęcia, filmy, emotikony, memy, grafiki. Nicholas Mirzoeff (2016) pisał o aktywizmie wizualnym jako nowym sposobie zmieniania rzeczywistości społecznej. Analiza tych form jest pilna i ważna, ponieważ obserwujemy obecnie kilka nasilających się tendencji i procesów.
Chodzi o personalizację polityki, zmiany w samym sposobie prowadzenia polityki, przemiany debaty publicznej: z jednej strony jej rosnącą wizualność, a z drugiej dominację tożsamości zamiast interesów oraz celebrytów w miejsce dyplomatów. Rośnie też grupa osób, które nie są zainteresowane tematami politycznymi $\mathrm{w}$ tradycyjnym rozumieniu, ale na przykład śledzą prywatne profile polityków w mediach społecznościowych. Można się zastanawiać, czy młodzi wyborcy wkrótce $\mathrm{w}$ ogóle nie będą poznawać programów wyborczych partii, ale z zaangażowaniem obserwować profile polityków na Instagramie.

Przyjrzyjmy się zatem, co polityków i badaczy polityki interesuje w Instagramie. Niewątpliwie stał się on już standardowym narzędziem w rękach sztabowców i specjalistów od PR (Kampka, Molek-Kozakowska 2020). Na pewno jest platformą o dużym potencjale dla budowania świadomości obywatelskiej, dumy i wspólnoty narodowej, co potwierdza analiza profilu premiera Kanady, Justina Trudeau, nazywanego selfie-premierem, który na Instagramie przedstawia się jako dynamiczny, pracowity lider reprezentujący różne grupy społeczne, podejmujący ważne społeczne kwestie, będący jednocześnie sympatycznym i pozytywnym człowiekiem (Lalancette, Raynauld 2019).

Polityczna komunikacja wizualna w mediach społecznościowych otwiera nowe możliwości docierania do odbiorców i pokazywania im życia polityków. Widzimy różne typy zachowań i scen prywatne chwile z rodziną i przyjaciółmi, zawodowe aspekty życia politycznego, codzienną pracę polityka, wystąpienia $\mathrm{w}$ mediach, udział $\mathrm{w}$ ważnych wydarzeniach - ceremoniach i protestach (Poulakidakos, Giannouli 2019: 192). Te różnorodne sposoby przejawiania się personalizacji polityki bardzo czę- 
sto towarzyszą zjawisku depolitycyzacji publicznego dyskursu - chodzi przede wszystkim o przesunięcie uwagi z kwestii ideologicznych na sprawy związane ze stylem życia (choć oczywiście styl życia również bywa sprawą ideologii). Pokazywanie stylu życia polityka buduje wyobrażenie o jego cechach charakteru czy poglądach politycznych (Poulakidakos, Giannouli 2019: 193). Instagram skłania przy tym raczej do pozytywnej autopromocji, a nie ataków na przeciwników (Poulakidakos, Giannouli 2019: 202), co odróżnia tę platformę od Twittera czy Facebooka.

Istotne z punktu widzenia badań nad dyskursem jest pytanie o pozycję i cele nadawcy. Media społecznościowe $\mathrm{z}$ reguły traktowane były jako potencjalne narzędzie opozycji i marginalizowanych grup, z równym powodzeniem mogą jednak służyć autorytarnej władzy (Avedissian 2016). Strategie dyskursywne partii zależne są od jej miejsca na scenie politycznej i głównego celu przekazu - czy będzie to propagowanie programu wyborczego, mobilizowanie wyborców, czy promowanie głównych kandydatów (Turnbull-Dugarte 2019). Pytanie o wizerunek, jaki partia chce stworzyć, jest interesujące chociażby w kontekście populizmu, który może być definiowany wizualnie na różne sposoby (Gimenez, Schwarz 2016).

Wizualność mediów społecznościowych współgra ze zmianami dotyczącymi partycypacji politycznej. Choć większe zainteresowanie w badaniu komunikacji politycznej budzi zawsze przekaz od decydentów do zwykłych ludzi i można zaobserwować tendencję do traktowania komunikacji internetowej jako mniej znaczącej, trywialnej, to jednocześnie chociażby wizualny humor okazuje się bardzo ważnym narzędziem protestu, przyciągającym uwagę, służącym edukacji, łączącym aktywistów. Badanie mobilizacji wyborców i jej przejawów w aktywności na Instagramie (Adi, Gerodimos, Lilleker 2018) pokazuje, jak wiele elementów może i powinno zostać uwzględnionych w analizie. Po pierwsze, w samych publikowanych zdjęciach można wskazywać na elementy czy cechy kompozycji, sygnalizujące zaangażowanie polityczne nadawcy (np. pokazywanie określonej aktywności, przestrzeni, flag, symboli). Relacja zdjęć i podpisów, implikowane emocje, odwołania do wartości, ważność politycznych kwestii, do których odnosiły się posty, relacje do polityków i do instytucji - to wszystko pozwala wskazać wzory obywatelskiej aktywności, ale przede wszystkim lepiej rozumieć analizowany proces polityczny (Gerodimos 2019: 65-66).

Pojawia się przy tym pytanie, co jest ważniejsze w dyskursie mediów społecznościowych: opanowanie słownika nowych mediów czy opanowanie słownika mitów politycznych obowiązującego w danym kręgu kulturowym. Anna Sanina (2014) analizowała aktywność polityczną zwykłych ludzi, która przejawiała się w ironicznym i humorystycznym komentowaniu rzeczywistości, i przekonywała, że wystarczy rozpoznawalność wewnętrznego dyskursu nowych mediów, aby móc w nim uczestniczyć. Analiza i interpretacja działań uczestników wymaga jednak znajomości obydwu wspomnianych słowników. W badaniu profili prezydenckich brak znajomości kontekstu wielokrotnie utrudniał kodowanie zdjęć. Jedna z grup pytań badawczych dotyczyła na przykład miejsca, które przedstawione jest na zdjęciu. Chodziło o zbadanie typu aktywności prezydenta, jakie miejsca odwiedza, czy częściej pokazywany jest jako gospodarz przyjmujący w pałacu, czy też reprezentant państwa odwiedzający różne miejscowości i kraje. W kilku przypadkach dużą trudnością było rozpoznanie przestrzeni, niepewność, czy to pałac prezydencki i niemożność 
rozpoznania miejsc znaczących dla danej społeczności.

Stamatis Poulakidakos i Iliana Giannouli (2019) wykorzystali profile na Instagramie, by badać zjawisko personalizacji polityki oraz wyróżnić jej „miękką” i „twardą" wersję. Personalizacja, jak wiadomo, może oznaczać różne rzeczy: personifikację polityki, czyli pokazywanie wydarzeń politycznych przez pryzmat uczestniczących $\mathrm{w}$ niej jednostek; orientację na osobowość, czyli skupianie się na cechach charakteru polityków (cechy wewnętrzne); intymizację, czyli przedstawianie ich hobby, strojów, stanu cywilnego (cechy zewnętrzne). Cechy wewnętrzne są silnie i naprawdę związane z osobowością danego polityka, cechy zewnętrzne - są bardziej zmienne, związane raczej z jego publicznym funkcjonowaniem. W literaturze przedmiotu znaleźć możemy różne wskaźniki personalizacji, należą do nich na przykład: pokazywanie rodziny, pokazywanie własnej przeszłości, zwłaszcza dzieciństwa i dorastania, pokazywanie czasu wolnego i życia miłosnego.

Badania związane $\mathrm{z}$ dyskursem politycznym i Instagramem nie tworzą spójnego obrazu i nie jest ich jak dotąd zbyt wiele, a wśród prac analizujących tę platformę stanowią mniejszość, jest to jednak ważna przestrzeń komunikacyjna, a znaczenie tego sposobu mówienia i pokazywania polityki najprawdopodobniej będzie rosło.

Krytyczna analiza dyskursu w odniesieniu do mediów społecznościowych jest trudnym zadaniem. Jak przypominają Veum i Undrum (2018), mamy prace z zakresu studiów kulturowych, które skupiają się na sposobach autokreacji i autorefleksji, znajdziemy też rozważania nad semiotycznymi reprezentacjami związanymi z ideologią i relacjami władzy. W przypadku analizy postów prezydenc- kich główne pytanie dotyczyło tego, czy prezydenckie konto na Instagramie służy budowaniu obrazu urzędu prezydenckiego jako takiego, wzmacnianiu tożsamości i wspólnoty narodowej oraz czy występują powtarzające się wzorce prezentacji prezydenta, które służą budowaniu jego etosu. Punktem wyjścia było przekonanie o celowym, świadomym i prymarnie perswazyjnym charakterze prezydenckich postów. Badając dyskurs wizualny (analiza dyskursu) o wyraźnym celu perswazyjnym (analiza retoryczna), w którym wykorzystane zostały symbole (analiza semiotyczna), mamy do czynienia ze swoistym splotem metodologicznym, świetnie to zresztą pokazują Anti Randiviir i Paul Cobley (2010), wymieniając jako podejścia semiotyczne prace socjolingwistyczne, CDA, antropologię kulturową czy pragmatyzm. Bliskość semiotyki, retoryki i analizy dyskursu jest czymś naturalnym w praktyce komunikacyjnej i czymś często spotykanym w praktyce badawczej.

Sama polityka i komunikacja polityczna zmieniły się i nadal zmieniają pod wpływem trzech czynników, na które trafnie wskazuje Paul Messaris (2019). Po pierwsze, wszechobecność telefonów komórkowych z możliwością nagrywania dźwięku i obrazu - politycy właściwie nigdy nie mogą być pewni, że nie są nagrywani (w dobrej lub złej wierze). Po drugie, mamy dziś do czynienia z bardzo szybkim rozwojem technologii pozwalających na daleko posunięte manipulacje obrazem - przetwarzanie istniejących zdjęć i filmów lub tworzenie realistycznych, ale $\mathrm{z}$ gruntu nieprawdziwych wersji. Po trzecie, cyfryzacja i nowe technologie komunikacyjne sprawiają, że odbiorca ma coraz więcej narzędzi, by wybierać tylko to, co chce oglądać, co ogranicza możliwości wykorzystania tradycyjnych kanałów docierania z reklamą polityczną. $W$ tych zmienionych warunkach, gdy z jednej strony obrazów jest 
coraz więcej, ale z drugiej strony nie ma wśród nich za dużo miejsca na typowe kampanijne obrazy w pełni kontrolowane przez sztaby - rola mediów społecznościowych, w tym Instagrama, nabiera nowego znaczenia. Stają się one nową przestrzenią do skolonizowania przez polityków. Pytanie, czy będą zachowywać się tam jak Mowgli, który przyjął prawa dżungli, czy hiszpańscy konkwistadorzy w państwach Inków i Azteków.

$\mathrm{W}$ analizowanym materiale widać, jak różnie prezydenci traktują Instagram, dla jednych jest to mało istotne uzupełnienie kanałów komunikacji (na profilu prezydenta Francji co pewien czas publikowany jest zestaw zdjęć z jakiegoś okresu, co sprawia, że Instagram przypomina raczej Flickr), dla innych sposób na nawiązanie bardziej osobistych relacji z obywatelami (prywatne posty prezydenta Słowenii czy Polski). Warto przy tym pamiętać, że nowe narzędzia i możliwości komunikacji wykorzystywane są na równi przez samych polityków, ich zwolenników i oponentów. Teoretycznie zatem media społecznościowe zrównują szanse na dotarcie do potencjalnych wyborców. W praktyce dostęp i interaktywność kontaktów zależne są od wielu czynników.

Przy obecnym wzroście zainteresowania w socjologii przekazami wizualnymi potrzebne jest rozwijanie narzędzi, które pozwolą uchwycić, zakodować i analizować ogromną liczbę nowych, wizualnych, znaczących społecznie interakcji. Krytyczne uwagi Romana Gerodimosa (2019: 54), że w rosnącym zalewie prac socjologicznych i politologicznych zajmujących się wizualnością za mało jest refleksji metodologicznej, poszukiwań rozwiązań analitycznych, procedur badawczych, które mogłyby się sprawdzić w więcej niż jednym, konkretnym przypadku, są częściowo słuszne. Oczekiwanie, że uda się stwo- rzyć podręcznikowy model, uniwersalny przepis, jak badać materiały wizualne w kontekście działań obywatelskich czy politycznych z jednej strony jest zrozumiałe, z drugiej jednak utopijne. Gerodimos ironicznie stwierdza, że o ile w przypadku słów i liczb jesteśmy przekonani, że możemy wprowadzić systematyczną i rygorystyczną analizę, o tyle obraz wymyka się takiej możliwości. Pewne jest jednak, że w przypadku analizy obrazu i analizy dyskursu nie można wskazać jedynej słusznej drogi, nawet jeśli badacze będą pracować na tym samym materiale (zob. Stubbe i in. 2013; Rancew-Sikora 2017; Stachowiak 2017) lub pytać o podobne zjawiska. Nie ma zresztą najmniejszej potrzeby, by opracować i przedstawić jako jedyny obowiązujący katalog procedur badawczych, ponieważ sytuacyjność i kontekst są kluczowe w analizie komunikacji w ogóle (Bielecka-Prus 2012).

Media społecznościowe stają się dziś głównym „frontem walki wyborczej”, co jest efektem ewolucji od czasów kampanii wyborczej Baracka Obamy na Facebooku czy Donalda Trumpa na Twitterze. Selfie, memy i udostępnianie zdjęć to elementy nowej wizualnej kultury obywatelskiej. Wielkie narracje, autorytety polityków i ekspertów zmagają się dziś z wyzwaniami kultury cyfrowej, a uwaga komunikacji politycznej skupia się dziś na spersonalizowanym, precyzyjnie dopasowanym do odbiorcy, a często jeszcze stworzonym przez tego odbiorcę przekazie (Gerodimos 2019). Duża część analiz dotyczy kampanii (prezydenckiej lub parlamentarnej) lub protestów i publicznych manifestacji. Brak pogłębionych badań codziennych politycznych aktywności i obecności kwestii politycznych w codziennej komunikacji jest zrozumiały, gdy weźmiemy pod uwagę, że w przypadku prasy, radia, telewizji łatwo jest określić okres analizy (Geronimos 2019: 60), tymczasem w komunikacji online, która jest epizo- 
dyczna, chaotyczna, nielinearna, bardzo trudne jest już samo zgromadzenie danych, których dobór dałoby się obronić ze względu na reprezentatywność.

Dzielenie się zdjęciami jest dziś powszechnym i zwyczajnym elementem ekologii mediów społecznościowych, codziennym doświadczeniem ich użytkowników, co przekłada się na nasze relacje wobec siebie, na to, jak postrzegamy i konstruujemy poczucie , ja". Zdjęcie/film przed opublikowaniem może być dowolnie przekształcane, wybierane, jest to strategiczna, przemyślana komunikacja, o wyraźnie perswazyjnym nastawieniu, mająca wywrzeć określone wrażenie na odbiorcy. W analizie przekazów prezydenckich ciekawe było porównanie relacji na Instagramie z wydarzeń, w których kilku prezydentów uczestniczyło jednocześnie, w omawianym okresie był to szczyt klimatyczny w Katowicach czy posiedzenie ONZ. Dobór udokumentowanych scen służy budowaniu całkowicie odmiennych wizerunków. Prezydent Finlandii zamieszcza przyjacielskie selfie ze znanym artystą, którego spotkał w samolocie do Nowego Yorku, większość prezydentów publikuje zdjęcie uwieczniające ich przemówienie, prezydent Austrii pokazuje się na dworcu kolejowym i dopiero opis zdjęcia i hasztagi wyjaśniają, że jest to ekologiczny wybór środka transportu na szczyt klimatyczny.

W przypadku badania profili prezydenckich stosunkowo łatwe było wskazanie powtarzających się wzorów przedstawień (Kampka 2019). Można było określić, na ile prezydenci przyjmują strategię ujawniania szczegółów z życia prywatnego (jedynym, który często korzystał z tego typu narracji, okazał się prezydent Słowenii). Wskazanie typowych sposobów reprezentacji niewiele mówi jednak o charakterze całego procesu komunikacji. Dopiero połączenie obrazu i tekstu opisu (lub wskazanie braku takiego opisu) oraz odniesienie całości komunikatu do kultury politycznej danego kraju pozwoli nie tylko odnotować, co prezydent pokazuje, ale także, jakie ma to znaczenie. Odpowiedź na pytanie, czy prezydenci wykorzystują Instagram do budowania i umacniania wspólnoty narodowej, jest twierdząca, udało się zrekonstruować pewien typ wizualnego dyskursu - reprezentacji urzędu prezydenckiego. Jednakże zrozumienie i interpretacja zaobserwowanych wzorów są niemożliwe bez uwzględnienia drugiego elementu Instagramowych postów - opisów i ewentualnych komentarzy.

\section{Podsumowanie}

Obraz ma wyjątkowy charakter, można na niego patrzeć jak na „medium w mediach” poprzez jego wieloznaczność i wielofunkcyjność (Stoellger 2015: 21). Obrazy z jednej strony są przejawami systemu norm, wartości i przekonań, ale z drugiej strony pozwalają nam w tym systemie uczestniczyć. Nie są jedynie reprezentacją na przykład naszego stylu życia, ale po prostu są jego częścią (Stoellger 2015: 20). W przypadku zdjęć oglądanych i publikowanych na Instagramie twierdzenie to nabiera szczególnego znaczenia. Jeśli dla wielu, zwłaszcza młodych, użytkowników jedynym obrazem polityki, jaki do nich dociera, będzie to, co zobaczą jako instastory, rodzi to poważne pytania o ich rozumienie polityki i formy partycypacji politycznej. A jednocześnie implikuje to ogromne wyzwania dla nadawców politycznych.

Richard Howells (2003), przedstawiając, czym jest kultura wizualna i czego musimy się uczyć, by móc w pełni w niej uczestniczyć, z dużą ostrożnością podchodził do problematyki wizualności w nowych mediach. Wskazywał między innymi na następujące problemy: dezaktualizację ustaleń badaczy 
ze względu na błyskawiczne zmiany zachodzące w nowych mediach oraz trudności ze wskazaniem kluczowych, podstawowych pojęć i koncepcji, które pozwalałyby objąć różnorodność nowych mediów. Jeśli zgodzimy się z jego opinią, że nowe media to opowieść, która właśnie jest opowiadana (Howells 2003: 246), dlatego wciąż brakuje nam wszystkich danych, by ją w pełni zrozumieć, przeanalizować i zinterpretować, zastanówmy się, na czym w takim razie możemy się skupić. Przede wszystkim - na języku, w którym toczy się ta opowieść. Dlatego tak ważne jest poznanie nowych praktyk dyskursywnych, które pojawiają się w nowych mediach, i stąd konieczność poznania „codzienności, zwyczajności” (platform vernacular) danego medium. Użyteczne są jednak także wszelkie narzędzia pozwalające zrozumieć przekaz wizualny jako taki. Po drugie - możemy rozpoznawać wątki, postacie i symbole pojawiające się $\mathrm{w}$ tej opowieści. Tutaj z pomocą przychodzą te wszystkie dyscypliny, które pozwolą nam zrozumieć szeroki kontekst działania - ekonomiczny, psychologiczny, kulturowy, historyczny.

Analiza fotografii na Instagramie, pozostającej tam - niezależnie od liczby publikowanych filmików główną formą przekazu skłania do przywoływania zjawisk obserwowanych przez badaczy społecznych od XIX wieku. Po pierwsze, chodzi o wykorzystanie potencjału zdjęć jako narzędzia reklamy i wiązania jej z konsumpcją. Wizualna prezentacja produktu i jego tekstowy opis to połączenie dwóch kanałów przekazu, które skutecznie pełni funkcję perswazyjną, czyli służy przekonaniu do nabycia czy używania danego produktu. Ten marketingowy wymiar fotografii na Instagramie jest bardzo wyraźny. Wiele firm i marek traktuje tę platformę jako jedną z najważniejszych dziś ścieżek promocji. Te same mechanizmy wykorzystywane są w wizualnej perswazji politycznej, zwłaszcza w okresie kampanii wyborczej. Po drugie, analizując wizualny dyskurs mediów społecznościowych, warto odnieść się także do obserwacji socjologów miasta, związanych ze stylem życia w mieście - wielością bodźców wizualnych, możliwością obserwacji ludzi, ich zachowań, ubiorów, przedmiotów codziennego użytku (Clarke 2005). Zdjęcia publikowane na Instagramie tworzą swoistą mozaikę pokazującą życie codzienne różnych grup społecznych, nawet jeśli jest to wyidealizowany obraz. A zatem w analizie dyskursu wizualnego na Instagramie wykorzystać możemy dorobek socjologów miasta, socjologów codzienności.

Jakościowa analiza dyskursu wizualnego w mediach społecznościowych z całą pewnością może być wspierana przez analizę ilościową, obejmującą wielkie zbiory danych. W tym przypadku interdyscyplinarność badań wiąże ze sobą nauki ścisłe i humanistyczne czy społeczne. O ile jednak wskazanie pewnych prawidłowości pozwala ukierunkować uwagę badacza na istotne (z racji swojej powszechności) zjawiska, o tyle do zrozumienia, w jaki sposób w obrazach krążących w mediach społecznościowych są tworzone i przekazywane znaczenia, utrwalane ideologie, negocjowane normy komunikacyjne, dzielone wartości i stereotypy - niezbędna wydaje analiza jakościowa. W tym przypadku, jeśli chcemy badać znaczenie przekazów, na pierwszy plan wysuwa się semiotyka, retoryka, a także różnorodne tradycje badania fotografii, filmu i wzornictwa. Gdy jednak pragniemy skupić się raczej na interaktywności - z pomocą przychodzi antropologia kultury wizualnej, medioznawstwo i politologia. Każdy z analizowanych przypadków wymaga jednak indywidualnego rozpatrzenia i wypracowania najskuteczniejszych metod. Niezmienna pozostaje aktualność podstawowych pytań: kto, co i komu pokazuje, w jakim celu i z jakim skutkiem. 


\section{Bibliografia}

Adi Ana, Gerodimos Roman, Lilleker Darren G. (2018) 'Yes We Vote': Civic mobilization and impulsive engagement on Instagram. "Javnost-The Public", vol. 25, no. 3, s. 315-332.

Avedissian Karena (2016) Clerics, weightlifters, and politicians: Ramzan Kadyrov's Instagram as an official project of Chechen memory and identity production. "Caucasus Survey”, vol. 1, no. 4,1, s. 20-43.

Belting Hans (2007) Antropologia obrazu. Szkice do nauki o obrazie. Przełożył Mariusz Bryl. Kraków: Universitas.

Bielecka-Prus Joanna (2012) Problem kontekstu w teoriach komunikowania społecznego. „Studia Socjologiczne”, nr 1(204), s. 19-36.

Bossetta Michael (2018) The digital architectures of social media: Comparing political campaigning on Facebook, Twitter, Instagram, and Snapchat in the 2016 U.S. election. "Journalism \& Mass Communication Quarterly", vol. 95, no. 2, s. 471-496.

Clarke Adele E. (2005) Situational Analysis. London: SAGE Publications.

Cohen Rachel i in. (2019) \#bodypositivity: A content analysis of body positive accounts on Instagram. „Body Image”, vol. 29, s. 47-57.

Cortese Daniel K. i in. (2018) Smoking Selfies: Using Instagram to Explore Young Women's Smoking Behaviors. "Social Media + Society", July-September, s. 1-8.

Czyżewski Marek, Kowalski Sergiusz, Piotrowski Andrzej, red. (1997) Rytualny chaos. Studium dyskursu politycznego. Kraków: Wydawnictwo Aureus.

Delli Carpini Michael X. (2017) The Political Effect of Entertainment Media [w:] Kate Kenski, Kathleen Hall Jamieson, eds., The Oxford Handbook of Political Communication. New York: Oxford University Press, s. 851-870.

Döring Nicola, Reif Anne, Poeschl Sandra (2016) How gender-stereotypical are selfies? A content analysis and comparison with magazine adverts. "Computers in Human Behavior”, vol. 55, s. 955-962.

Foss Sonja (1994) A Rhetorical Schema for the Evaluation of Visual Imagery. "Communication Studies", no 45, s. 213-234.

Foss Sonja (2005) Theory of Visual Rhetoric [w:] Ken Smith i in., eds., Handbook of Visual Communication: Theory, Methods, and Media. Mahwah, NJ: Lawrence Erlbaum, s. 141-152.
Gemius/PBI (2019) Wyniki badania Gemius/PBI za grudzień 2018 [dostęp 10 stycznia 2019 r.]. Dostępny w Internecie: https:// www.gemius.pl/wszystkie-artykuly-aktualnosci/wyniki-badania-gemiuspbi-za-grudzien-2018.html.

Gerodimos Roman (2019) The Interdisciplinary Roots and Digital Branches of Visual Political Communication Research [w:] Anastasia Veneti, Daniel Jackson, Darren G. Lilleker, eds., Visual Political Communication. Cham: Palgrave Mcmillan, s. 53-73.

Gibbs Martin i in. (2014) \#Funerals and Instagram: Death, Social Media and Platform Vernacular. „Information, Communication\& Society", vol. 18, no. 3, s. 255-268.

Gimenez Elsa, Schwarz Natalie (2016) The visual construction of "the people" and "proximity to the people" on the online platforms of the National Front and Swiss People's Party. "Österreich Z Soziol”, vol. 41, s. 213-242.

Ging Debbie, Garvey Sarah (2018) Written in these scars are the stories I can't explain': A content analysis of pro-ana and thinspiration image sharing on Instagram. "New Media \& Society", vol. 20(3), s. 1181-1200.

Highfield Tim, Leaver Tama (2016) Instagrammatics and digital methods: Studying visual social media, from selfies and GIFs to memes and emoji. „Communication Research and Practices”, vol. 2, no. 1, s. 47-62.

Howells Richard (2003) Visual Culture. Cambridge: Polity.

Jenkins Henry, Ford Sam, Green Joshua (2018) Rozprzestrzenialne media. Jak powstaja wartości $i$ znaczenia w usieciowionej kulturze. Przełożył Michał Wróblewski. Łódź: Wydawnictwo Uniwersytetu Łódzkiego.

Kampka Agnieszka (2019) Bliżej ludzi czy bliżej gwiazd - prezydenci na Instagramie. „Kultura popularna”, nr 2, s. 37-48.

Kampka Agnieszka, Molek-Kozakowska Katarzyna (2020) Instagram w autoprezentacji politycznej. Analiza wizualna postów polskich kandydatów do europarlamentu w 2019. „Polityka i Społeczeństwo", nr 1(18), s. 41-62.

Karimova Gulnara (2020) Exploring Visual Framing Strategies, Sentiment, and Product Presentation Modality in Instagram Posts of Fashion Influencers. „Res Rhetorica”, no. 1, s. 86-106.

KhosraviNik Majid (2018) Social Media Critical Discourse Studies (SM-CDS) [w:] John Flowerdew, John Richardson, eds., The Ro- 
utledge Handbook of Critical Discourse Studies. New York: Routledge, s. 582-596.

KhosraviNik Majid, Unger Johann W. (2015) Critical Discourse Studies and Social Media: Power, Resistance and Critique in Changing Media Ecologies [w:] Ruth Wodak, Michael Meyer, eds., Methods of Critical Discourse Studies. London: SAGE, s. 206-233.

Kress Gunther, van Leeuwen Theo (2006) Reading Images: The Grammar of Visual Design. Oxon: Routledge.

Kuchta-Nykiel Monika (2020) Social media w Polsce i na świecie - najnowsze dane [dostęp 15 maja 2020 r.]. Dostępny w Internecie: 〈https://socialpress.pl/2020/02/social-media-w-polsce-i-naswiecie-najnowsze-dane».

Laestadius Linnea (2017) Instagram [w:] Sloan Luke, QuanHaase Anabel, eds., The SAGE Handbook of Social Media Research Methods. London: SAGE Publications, s. 573-592.

Lalancette Mireille, Raynauld Vincent (2017) The Power of Political Image: Justin Trudeau, Instagram, and Celebrity Politics. „American Behavioral Scientist", vol. 63, no 7, s. 888-924.

Lilleker Darren G., Veneti Anastasia, Jackson Daniel, eds. (2019) Visual Political Communication. Cham: Palgrave Mcmillan.

Liu Rendan, Suh Ayoung (2017) Self-Branding on Social Media: An Analysis of Style Bloggers on Instagram. „Procedia Computer Science", vol. 124, s. 12-20.

Locatelli Elisabetta (2017) Images of Breastfeeding on Instagram: Self-Representation, Publicness, and Privacy Management. "Social Media + Society", April-June, s. 1-14.

MacDowall Lachlan John, Souza Poppy de (2018) 'I'd Double Tap That!!': street art, graffiti, and Instagram research. „Media, Culture \& Society", vol. 40, no. 1, s. 3-22.

Manghani Sunil (2013) Image Studies. Theory and Practice. London, New York: Routledge.

Manovich Lev (2017) Instagram and Contemporary Image [dostęp 5 września 2019 r.]. Dostępny w Internecie: ‘ttp://manovich. net/content/04-projects/150-instagram-and-contemporaryimage/instagram_book_manovich_2017.pdf .

Mariani Massimo (2019) What Images Really Tell Us. Visual Rhetoric in Art, Graphic Design and Advertisement. Barcelona: Hoaki.
Matley David (2018) "Let's see how many of you mother fuckers unfollow me for this": The pragmatic function of the hashtag \#sorrynotsorry in non-apologetic Instagram posts. "Journal of Pragmatics", vol. 133, s. 66-78.

Messaris Paul (2019) The Digital Transformation of Visual Politics [w:] Anastasia Veneti, Daniel Jackson, Darren G. Lilleker, eds., Visual Political Communication. Cham: Palgrave Mcmillan, s. 17-36.

Mirzoeff Nicholas (2016) Jak zobaczyć świat. Przełożył Łukasz Zaremba. Kraków, Warszawa: Wydawnictwo Karakter, Muzeum Sztuki Współczesnej w Warszawie.

Newberry Christina (2019) 37 Instagram Stats That Matter to Marketers in 2020 [dostęp 20 maja 2020 r.]. Dostępny w Internecie: ‘https://blog.hootsuite.com/instagram-statistics/〉.

O'Halloran Kay L. i in. (2018) A Digital Mixed Methods Research Design: Integrating Multimodal Analysis With Data Mining and Information Visualization for Big Data Analytics. "Journal of Mixed Methods Research", vol. 12(1), s. 11-30.

Olson Lester C., Finnegan Cara A., Hope Diane S., eds. (2008) Visual Rhetoric: A Reader in Communication and American Culture. Los Angeles: SAGE.

Owen Diana (2017) New Media and Political Campaigns [w:] Kate Kenski, Kathleen Hall Jamieson, eds., The Oxford Handbook of Political Communication. New York: Oxford University Press, s. 823-835.

Phillips Nelson, Hardy Cynthia (2011) Discourse Analysis. Investigating Processes of Social Construction. Thousand Oaks: SAGE Publications.

Poulakidakos Stamatis, Giannouli Iliana (2019) Greek Political Leaders on Instagram: Between "Soft" and "Hard" Personalization [w:] Anastasia Veneti, Daniel Jackson, Darren G. Lilleker, eds., Visual Political Communication. Cham: Palgrave Mcmillan, s. 187-206.

Poulsen Soren Vigild (2018) Constructing the Corporate Instagram Discourse - a Critical Visual Discourse Approach. "Digital Age in Semiotics \& Communication", vol. 1, no. 1, s. 95-112.

Rancew-Sikora Dorota (2017) Analiza konwersacyjna audycji radiowej pośzięconej coachingowi [w:] Marek Czyżewski i in., red., Analiza dyskursu publicznego. Przeglad metod i perspektyw badawczych. Warszawa: Wydawnictwo Akademickie Sedno, s. 349-372.

Randiviir Anti, Cobley Paul (2010) Sociosemiotics [w:] Paul Cobley, ed., The Routledge Companion to Semiotics. London, New York: Routledge, s. 118-134. 
Rodriguez Nathian Shae, Hernandez Terri (2018) Dibs on that Sexy Piece of Ass: Hegemonic Masculinity on TFM Girls Instagram Account. „Social Media + Society", January-March, s. 1-12.

Rose Gilian (2010) Interpretacja materiałów wizualnych. Krytyczna metodologia badań nad wizualnością. Przełożyła Ewa Klekot. Warszawa: Wydawnictwo Naukowe PWN.

Sanina Anna G. (2014) Visual political irony in Russian new media. „Discourse, Context and Media”, no. 6, s. 11-21.

Serafinelli Elisa (2017) Analysis of Photo Sharing and Visual Social Relationships. Instagram as Case Study. „Photographies”, vol. 10, no. 1, s. 91-111.

Stachowiak Jerzy (2017) Analiza porządków uzasadniania. Studium nowego ducha kapitalizmu [w:] Marek Czyżewski i in., red., Analiza dyskursu publicznego. Przeglad metod i perspektyw badawczych. Warszawa: Wydawnictwo Akademickie Sedno, s. 373-402.

Statista (2020) Distribution of Instagram users worldwide as of January 2018, by age group [dostęp 10 stycznia 2020 r.]. Dostępny w Internecie: https://www.statista.com/statistics/325587/instagram-global-age-group/.

Stĺhl Matilda, Kaihovirta Hannah (2019) Exploring visual communication and competencies through interaction with images in social media. „Learning, Culture and Social Interaction”, no. 21, s. 250-266.

Stoellger Phillip (2015) Living Images and Images We Live By. What Does It Mean to Became a Living Image? [w:] András Benedek, Kristóf Nyíri, eds., Beyond Words. Pictures, Parables, Paradoxes. Frankfurt am Main: Peter Lang, s. 17-34.
Stromer-Galley Jennifer (2017) Political Discussion and Deliberation Online [w:] Kate Kenski, Kathleen Hall Jamieson, eds., The Oxford Handbook of Political Communication. New York: Oxford University Press, s. 837-850.

Stubbe Maria i in. (2013) Interakcja w miejscu pracy z perspektywy kilku podejść dyskursywnych. „Przegląd Socjologii Jakościowej”, t. 9, nr 1, s. 112-129.

Tiidenberg Katrin, Baym Nancy K. (2017) Learn It, Buy It, Work It: Intensive Pregnancy on Instagram. "Social Media + Society", January-March, s. 1-13.

Turnbull-Dugarte Stuart J. (2019) Selfies, Policies, or Votes? Political Party Use of Instagram in the 2015 and 2016 Spanish General Elections. "Social Media + Society" April-June s. 1-15.

Van Leeuwen Theo, Jewitt Carey (2004) Visual Meaning: a Social Semiotic Approach [w:] Theo van Leeuwen, Jewitt Carey, eds., The Handbook of Visual Analysis. London: SAGE, s. 134-155.

Veum Aslaug Moland, Undrum Linda Victoria (2018) The selfie as a global discourse. „Discourse \& Society”, vol. 29, no. 1, s. 86-103.

Wielgosz Marcin (2017) Usefulness and potential benefits of analyzing new media from the perspective of L. Manovich's soft technological determinism - the case of Instagram and smartphone. "Social Communication", vol. 2, s. 6-13.

Zappavigna Michele, Zhao Sumin (2017) Selfies in 'mommyblogging': An emerging visual genre. „Discourse, Context \& Media”, vol. 20, s. 239-247.

\section{Cytowanie}

Kampka Agnieszka (2020) Wizualna analiza dyskursu na Instagramie - możliwości i ograniczenia. „Przegląd Socjologii Jakościowej”, t. 16, nr 4, s. 86-103 [dostęp dzień, miesiąc, rok]. Dostępny w Internecie: ‘www.przegladsocjologiijakosciowej.org〉. DOI: http:// dx.doi.org/10.18778/1733-8069.16.4.05

\section{Visual Discourse Analysis on Instagram: Possibilities and Limitations}

Abstract: The article discusses the challenges that discourse researchers are facing with regard to new media. The author presents the characteristics of Instagram as a communication space as well as the use of Instagram in the political discourse. Based on previous research and the example of the analysis of the European presidents' profiles, the greatest difficulties in researching this social platform have been identified, namely: the inseparability of the image and text, the need to take into account the broad technological and cultural context, and the resultant need for an interdisciplinary approach.

Keywords: visuality, Instagram, discourse analysis, multimodality, new media 